\title{
Panorama das pesquisas toponímicas no Brasil
}

\author{
Cezar Alexandre Neri SANTOS (1) \\ Universidade Federal de Alagoas (UFAL)
}

\section{RESUMO}

Esta resenha destaca os principais tópicos apresentados na mesa redonda A pesquisa toponímica no Brasil: estudos contemporâneos, que compôs a programação de conferências remotas Abralin Ao Vivo, durante o período de pandemia pela Covid-19. Com a finalidade de "fornecer à comunidade acadêmica na área de Linguística e demais interessados um panorama do estado de arte da pesquisa toponímica no Brasil", os/as debatedores/as proporcionaram o conhecimento e a discussão de relevantes aspectos teórico-metodológicos e aplicados em relação aos nomes geográficos do país, especialmente nas últimas décadas, contribuindo para a divulgação científica e para a interlocução entre pares e constatando que os projetos de pesquisa na área têm se expandido.

\section{ABSTRACT}

This review highlights the main topics presented in the panel Place-name research in Brazil: contemporary studies, which constituted an online event at Abralin Ao Vivo during Covid-19 pandemic period. Aiming "to provide the academic community in the area of Linguistics and other interested with an outline of place-name research in Brazil", debaters succeed in discussing relevant theoretical, methodological and applied aspects concerning national toponyms, especially those carried out in recent decades, contributing to scientific dissemination and to peer interaction and concluding that Brazilian place-name research has been increasing.

\section{PALAVRAS-CHAVE}

Toponímia brasileira. Toponímia Histórica. Topônimos em Libras.

\section{KEYWORDS}

Brazilian place-names. Historical Toponomastics. Brazilian Sign Language. 


\section{REVISTA DA ABRALIN}

A mesa redonda A pesquisa toponímica no Brasil: estudos contemporâneos compôs a programação de conferências remotas Abralin Ao Vivo, durante o período de pandemia pela Covid-19. Ocorrida em 23 de julho de 2020, foi moderada pela prof. ${ }^{a}$ Dr. ${ }^{a}$ Karylleila dos Santos Andrade (UFT), e teve como objetivo "fornecer à comunidade acadêmica na área de Linguística e demais interessados um panorama do estado de arte da pesquisa toponímica no Brasil" (A PESQUISA, 2020). Para essa tarefa, a prof. ${ }^{a}$ Dr. ${ }^{a}$ Aparecida Negri Isquerdo (UFMS/CNPq), a prof. ${ }^{a}$ Dr. ${ }^{a}$ Maria Cândida Trindade Costa de Seabra (UFMG) e o prof. Dr. Alexandre Melo de Sousa (UFAC), nessa ordem, durante duas horas e trinta minutos, com tradução simultânea para a Língua Brasileira de Sinais (Libras), apresentaram aspectos teórico-metodológicos e aplicados em relação a pesquisas tradicionais e inovadoras de nomes geográficos do país, especialmente nas últimas décadas.

Como destaca o texto de chamada do evento, os estudos toponímicos configuram-se área de pesquisa consolidada no Brasil, especialmente vinculados a cursos de graduação e de pós-graduação em Letras e Linguística em todas as regiões do país (A PESQUISA, 2020). Com mérito, os/as debatedores/as destacaram essa atividade como uma celebração ao legado da professora Dr. ${ }^{a}$ Maria Vicentina de Paula do Amaral Dick (USP), responsável pela delimitação e pelo status da Toponímia nacionalmente, constituindo referência obrigatória para pesquisadores/as que se dedicam ao estudo dos nomes de lugares.

Em fala intitulada A Toponímia como área de investigação linguística no Brasil: um panorama, a professora Isquerdo enfatizou a filiação da toponímia à ciência linguística e apresentou um esclarecedor estado da arte das pesquisas toponímicas, destacando a tradição teórico-metodológica galoibérica da toponímia brasileira, a exemplo de autores como Albert Dauzat, Leite de Vasconcellos, Joseph Piel, dentre outros. Ao constatar o crescimento exponencial de pesquisas regionais produzidas em forma de Dissertações e de Teses na última década, Isquerdo apresentou uma periodização em quatro fases para os estudos toponímicos brasileiros (1901-1979; 1980-1989; 1990-2009; e 2010presente), atualizando sua proposta tripartite anterior (ISQUERDO, 2012).

Ao destacar objetivos e escopo do que se convencionou atlas toponímicos, Isquerdo lista os principais projetos de abrangência estadual, a exemplo do Atlas Toponímico do Mato Grosso do Sul (ATEMS), sob sua coordenação, informando alguns produtos bibliográficos desse grupo. Esta pesquisadora ainda assinala a importância de abordagens teórico-metodológicas seguras, por exemplo, em relação à coleta de topônimos em bases cartográficas e à codificação, que, no Brasil, tem sido norteada por fichas lexicográficas, como proposto por Dick (2004). Também reitera a importância do desenvolvimento de pesquisadores com sólida formação teórico-metodológica em Linguística, bem como a formação de bancos de dados em equipe, ao justificar que futuros financiamentos devem ser destinados a pesquisas dessa natureza. Enfatiza, ainda, a relação entre Toponímia e áreas afins, tais como Dialetologia, Etnolinguística, Cartografia, Geografia e História.

Em sua fala intitulada Toponímia Histórica, a professora Maria Cândida Seabra, coordenadora do projeto Atlas Toponímico de Minas Gerais (ATEMIG), enfatiza o caráter interdisciplinar dos nomes de lugares, especialmente a interface com a Linguística Histórica. Seabra também caracteriza aspectos inerentes aos nomes próprios, especialmente aos nomes de lugares, como a motivação, a 


\section{REVISTA DA ABRALIN}

identificação e a referencialidade, bem como destacando memória e identidade toponímicas como parte de investigações linguísticas e culturais.

Ratificando o argumento de Isquerdo, Seabra destaca algumas diretrizes teórico-metodológicas, como as do método de áreas de Albert Dauzat (1926), que podem ser sumarizadas como o estabelecimento das camadas dialetais; a pesquisa das raízes formadoras dos topônimos; a reconstituição etimológica das formas antigas de nomeação, oriundas de substratos e adstratos linguísticos; e pesquisa em documentos históricos, segundo Dick (2000, p. 231). Essa professora também descreve e analisa processos de variação toponímica, especialmente diatópicos e diacrônicos, com exemplos de corpora coletados em documentos textuais - oficiais e não oficiais - e cartográficos históricos.

Tomando o corpus constituído no Projeto ATEMIG, bem como baseado em dados de estados vizinhos, sua exposição expõe bons exemplos de tratamento sócio-histórico e dialetal com dados toponímicos. Por exemplo, Seabra destaca resultados de estudos interinstitucionais, como a identificação de um continuum toponímico do item botânico buriti em Minas Gerais e em Mato Grosso do Sul. Outro resultado de ação interinstitucional constituiu um conjunto de atividades de patrimonialização toponímica, por meio da preservação, da catalogação e da exposição digital e/ou museológica de dados. Por fim, ao citar Martínez Lema (2018, p. 9), reforça a retroalimentação entre as disciplinas Toponímia e Linguística Histórica.

Um aspecto inovador da mesa se deu pela temática abordada pelo professor Alexandre Melo de Sousa, que descreveu e analisou a Toponímia em Libras - Língua Brasileira de Sinais -, idioma cooficial do Brasil desde 2002. O professor afirma que topônimos em língua oralizada e na Libras, língua visual-espacial amplamente usada pela comunidade surda brasileira, coexistem socialmente, não sendo os sinais-nomes, necessariamente, transliterações de signos linguísticos em língua portuguesa. Dada a natureza desse corpus, Sousa didaticamente apresenta especificidades daquele sistema linguístico, como a adoção do signwriting como sistema de escrita dos sinais-nome; o destaque da iconicidade como relevante propriedade do léxico toponímico em Libras, bem como descreve e analisa, nos níveis gramatical e semântico-referencial, sinais-nomes do estado do Acre. Ao destrinchar alguns procedimentos metodológicos, notadamente se percebe a adaptação do modelo de ficha lexicográfico-toponímica de Dick (2004), bem como uma coerente estratificação dos sujeitos da comunidade surda acreana para validação de dados.

Ao argumentar particularidades semântico-referenciais no cotejo de topônimos em Libras e em português brasileiro, ainda apresenta o Toponímia em Libras (SOUSA; QUADROS, 2019), web software autoral de acesso livre, um dos produtos de seu estágio de pós-doutoramento. Esse software tem funcionado como repositório dos sinais toponímicos acreanos e, segundo esse pesquisador, pode servir como um banco de dados mais abrangente, com a possibilidade de replicação junto a corpora de outros estados. Por fim, apresenta um estado da arte de pesquisas e de projetos brasileiros que envolvem topônimos em Libras, bem como parabeniza os intérpretes de Libras pelo auxílio na acessibilidade, destacando a oportunidade e a necessidade de dar visibilidade a estudos produzidos em regiões não hegemônicas do país, como é o caso do Acre. 


\section{REVISTA DA ABRALIN}

Após as três falas, Karylleila Andrade, coordenadora do projeto Atlas Toponímico de Origem Indígena do Estado do Tocantins (ATITO), na função de moderadora, salienta a ativa interação nos chats, cujo público se constitui maciçamente de professores e de pesquisadores de universidade públicas do país, mas também de estudantes e de interessados na temática. Pela limitação do tempo, Andrade procedeu à seleção de alguns questionamentos, o que produziu um debate sobre os desafios teórico-metodológicos e analíticos e prospecções das pesquisas toponímicas no Brasil, especialmente no contexto atual de parcos financiamentos; tendência de aumento de projetos de pesquisa regionais autônomos, com aplicações em corpora toponímicos diversificados, algo já previsto pela própria professora Dick; considerações sobre manutenção/mudança toponímica com referentes de caráter ditatorial-totalitário; funções e limitações de órgãos oficiais, como o IBGE, quanto ao georreferenciamento, à reambulação e à cartografação de dados toponímicos, considerando as especificidades geográficas, político-econômicas e sócio-históricas de um país com dimensão continental. Na fala final dos/das debatedores/as e da moderadora, o agradecimento à audiência e à Associação Brasileira de Linguística pela promoção do evento e pelo convite foi uníssono.

Quanto aos estudos contemporâneos no âmbito da Toponímia, podemos adicionar outras questões que têm ampliado esse quadro. Especialmente a partir da década de 1990, a interface com áreas como Sociolinguística, Estudos Culturais, Contato Linguístico e Cognição tem sido caracterizada como Sociotoponímia (HOUGH, 2016), valendo-se de corpora toponímicos não prototípicos e ampliando conceitual e metodologicamente o que se entende por nomes de lugares. Também destacamos a importância tanto da internacionalização de pesquisas toponímicas brasileiras, uma ação tímida, mas em desenvolvimento, quanto do conhecimento de estudos contemporâneos promovidos internacionalmente.

Como adendo às reflexões acerca da temática e das discussões pertinentemente apresentadas, podemos destacar que atividades desse quilate se mostram necessárias, dentre outros motivos, para apresentar a leigos e a cientistas da língua(gem) de outras áreas que a toponímia não se resume a "[...] um rol de vocábulos quase exclusivamente de origem tupi, seguido de uma provável etimologia, esgotando-se aí, nesse procedimento, os objetivos e as pretensões da matéria", como bem assinalou o professor Carlos Drumond (cf. DICK, 1990, p. II). Cremos que esse objetivo foi claramente atingido pelos/as debatedores/as e que atividades online como essa contribuem para a divulgação científica e para a interlocução entre pares sobre aspectos próprios ou lacunares dos estudos toponímicos nacionais. Assim, recomendamos a professores/as, pesquisadores/as e entusiastas se apropriem dessas discussões como um panorama de abordagens científicas em relação aos nomes de lugares no Brasil.

\section{REFERÊNCIAS}

A PESQUISA Toponímica no Brasil: estudos contemporâneos. Mesa Redonda debatida por Aparecida Negri Isquerdo, Maria Candida Trindade da Costa Seabra e Alexandre Melo de Sousa [s.l., s..n.], 2020. 1 vídeo (2h 37 min 10s). Publicado pelo canal da Associação Brasileira de Linguística. Disponível em: https://www.youtube.com/watch?v=8YcU-obkeuc. Acesso em: 26 jul. 2020. 


\section{REVISTA DA ABRALIN}

DICK, Maria Vicentina de Paula do Amaral. Rede de conhecimento e campo lexical: hidrônimos e hidrotopônimos na onomástica brasileira. In: ISQUERDO, Aparecida Negri; KRIEGER, Maria da Graça (Org.). As ciências do léxico. v. II. Campo Grande: EdUFMS, 2004, p. 121-130.

DICK, Maria Vicentina de Paula do Amaral. A Investigação Lingüística na Onomástica Brasileira. Estudos de Gramática Portuguesa III. Frankfurt am Main, v. III, p. 217-239, 2000.

DICK, Maria Vicentina de Paula do Amaral. Prefácio. In: DICK, Maria Vicentina de Paula do Amaral. Toponímia e antroponímia do Brasil. Coletânea de Estudos. 2. ed. São Paulo: Serviço de Artes Gráficas da FFLCH/USP, 1990. 224p.

HOUGH, Carole (Ed.) The Oxford Handbook of Names and Naming. Series: Oxford handbooks in linguistics. Oxford: Oxford University Press, 2016.

ISQUERDO, Aparecida Negri. La recherche toponymique au Brésil: une perspective historiographique. Cahiers de lexicologie: Revue internationale de lexicologie et lexicographie, n. 101, p. 15-36, 2012.

MARTÍNEZ LEMA, Paulo. Toponímia e Fonética Histórica no domínio galego-português: notas para uma linha de trabalho. Estudis Romànics [Institut d'Estudis Catalans], v. 40, p. 7-36, 2018. DOI: 10.2436/20.2500.01.213.

SOUSA, Alexandre Melo de; QUADROS, Ronice Müller de. O web software Toponímia em Libras: pesquisa e ensino. In: SOUSA, Alexandre Melo de Sousa; GARCIA, Rosane; SANTOS, Tatiane Castro dos (Orgs.). Perspectivas para o ensino de línguas. v. 3. São Carlos: Pedro \& João Editores. p. 11-33, 2019.

STEWART, George Rippey. A classification of place names. Names, v. 2, n. 1, p. 1-13, 1954. DOI: 10.1179/nam.1954.2.1.1 